\title{
Highly Efficient AuPd/Carbon Nanotube Nanocatalysts for the Electro-Fenton Process
}

\author{
Meng Sun, ${ }^{[a, c]}$ Gong Zhang, ${ }^{[a, c]}$ Yang Liu, ${ }^{[b]}$ Huijuan Liu, ${ }^{[a]}$ Jiuhui Qu, ${ }^{*[a]}$ and Jinghong Li ${ }^{*[b]}$
}

Abstract: Development of novel nanocatalysts for the highly efficient in situ synthesis of $\mathrm{H}_{2} \mathrm{O}_{2}$ from $\mathrm{H}_{2}$ and $\mathrm{O}_{2}$ in the electro-Fenton (EF) process has potential for the remediation of water pollution. In this work, AuPd/carbon nanotube (CNT) nanocatalysts were successfully synthesized by the facile aggregation of AuPd bimetals on CNTs. Characterization by X-ray diffraction, transmission electron microscopy, and X-ray photoelectron spectroscopy indicated that pure AuPd bimetallic heterogeneous nanospheres $(\approx 20 \mathrm{~nm})$ were well dispersed outside the CNTs, which resulted in better catalytic performance than $\mathrm{Pd} / \mathrm{CNTs}$ alone: $0.36 \mathrm{M} \mathrm{H}_{2} \mathrm{O}_{2}$ was synthe- sized; $0.05 \mathrm{M} \mathrm{Fe}^{2+}$ optimally initiated the EF process due to the superior in situ $\mathrm{Fe}^{2+}$ regeneration; and the organic pollutant removal reached $100 \%$ at $37 \mathrm{~min}$, with a pseudo-firstorder kinetic constant $k_{1}=0.051 \mathrm{~min}^{-1}$. Moreover, structural insights before/after catalysis revealed that Au strengthened the construction of the nanocrystals, avoided negative deactivation caused by AuPd agglomeration, and immobilized the active $\mathrm{Pd}(111)$. The catalytic stability of AuPd/CNTs over ten cycles implied long durability and promising applications of this material.

\section{Introduction}

Fenton oxidation, as an advanced oxidation process, has aroused great interest in water remediation over recent decades due to the formation of the highly reactive and nonselective hydroxyl radical ( $\mathrm{OH}$, oxidation potential: $2.8 \mathrm{~V}){ }^{[1]}$ The produced $\mathrm{OH}$ enables superior properties of the method, that is, nonselective, strongly oxidizing, and high reactivity, which contribute to the efficient removal and mineralization of complex contaminants, such as oil wastes, dyes, bromate, chromium, arsenic, and synthetic organic wastewater. ${ }^{[2]}$ However, its application is limited by such drawbacks as the difficulty in controlling the dose of ferrous salts for catalytic oxidation, and the high cost and danger in the production, transportation, and storage of $\mathrm{H}_{2} \mathrm{O}_{2}$. Therefore, the electro-Fenton (EF) process has been under intense study owing to its continuous in situ

[a] M. Sun, G. Zhang, H. Liu, Prof. J. Qu

Key Laboratory of Drinking Water Science and Technology

Research Center for Eco-Environmental Sciences

Chinese Academy of Sciences, Beijing 100085 (China)

Fax: (+ 86) 10-6292355

E-mail:jhqu@rcees.ac.cn

[b] Y. Liu, Prof. J. Li

Department of Chemistry

Beijing Key Laboratory for Microanalytical Methods and Instrumentation Tsinghua University, Beijing 100084 (China)

Fax: $(+86)$ 10-62795290

E-mail:jhli@mail.tsinghua.edu.cn

[c] M. Sun, G. Zhang

University of Chinese Academy of Sciences Beijing 100039 (China)

Supporting information for this article is available on the WWW under http://dx.doi.org/10.1002/chem.201406676. generation of $\mathrm{H}_{2} \mathrm{O}_{2}$ from cathodes [Eq. (1)] and $\mathrm{Fe}^{2+}$ from anodes [Eq. (2)]. ${ }^{[3]}$ High-efficiency $\mathrm{H}_{2} \mathrm{O}_{2}$ requires electrode materials with high price and poor structural stability, such as synthetic boron-doped diamond, active carbon fiber, and gas diffusion electrodes. ${ }^{[4]}$ Furthermore, the sluggish kinetic process of oxygen reduction for $\mathrm{H}_{2} \mathrm{O}_{2}$ synthesis also depends strongly on the electrode materials, which complicates the implementation process and increases the cost.

$$
\begin{aligned}
& \mathrm{O}_{2}(\mathrm{~g})+2 \mathrm{H}^{+}+2 \mathrm{e}^{-}=\mathrm{H}_{2} \mathrm{O}_{2} \quad E^{\theta}=0.695 \mathrm{~V} \\
& \mathrm{Fe}^{2+}+2 \mathrm{e}^{-}=\mathrm{Fe} \quad E^{\theta}=-0.447 \mathrm{~V}
\end{aligned}
$$

Recently, a novel palladium-based catalyst showed great potential in direct synthesis of $\mathrm{H}_{2} \mathrm{O}_{2}$ during the EF process. ${ }^{[5]}$ The strategy can be summarized as follows. 1) Sufficient utilization of $\mathrm{H}_{2}$ and $\mathrm{O}_{2}$ released from electrodes [Eqs. (3) and (4)] in synthesizing $\mathrm{H}_{2} \mathrm{O}_{2}$ by electrolysis. 2) High efficiency of catalytic synthesis of $\mathrm{H}_{2} \mathrm{O}_{2}$ over the active surface of $\mathrm{Pd}$ atoms [Eq. (5)]. 3) Promotion of interfacial contact efficiency among catalysts, $\mathrm{O}_{2}$, and $\mathrm{H}_{2}$ in the three-electrode electrolysis system. The new process exhibited high performance in the degradation of many organic contaminants, including rhodamine $\mathrm{B}$, trichloroethylene, phenol, and toluene in wastewater and groundwater. ${ }^{[5 b, d, 6]}$ Nevertheless, the weaknesses of this Pd-based EF process should not be neglected. For instance, monometallic catalysts without specific surface decoration generally have lower catalytic activity than bimetallic/intermetallic catalysts, and the Fe@Fe $\mathrm{O}_{y}$ substrate has less structural stability in acid media than carbonaceous substrates. ${ }^{[7]}$ Importantly, particle agglomeration of Pd supported on Fe-containing substrates in acidic solution generally results in the deactivation of the composite 
catalysts. Thus, development of efficient and active bimetallic nanocatalysts supported on robust substrates with superior structure is essential for highly efficient catalysis in the EF process.

$$
\begin{aligned}
& 2 \mathrm{H}^{+}+2 \mathrm{e}^{-}=\mathrm{H}_{2} \quad E^{\theta}=0 \mathrm{~V} \\
& \mathrm{H}_{2} \mathrm{O}+2 \mathrm{H}^{+}+2 \mathrm{e}^{-}=\mathrm{H}_{2} \mathrm{O}_{2} \quad E^{\theta}=0.695 \mathrm{~V} \\
& \mathrm{O}_{2}(\mathrm{~g})+\mathrm{H}_{2}(\mathrm{~g}) \rightarrow \mathrm{H}_{2} \mathrm{O}_{2}
\end{aligned}
$$

AuPd bimetallic nanocomposite catalysts with core-shell structures, ${ }^{[8]}$ specific shapes, ${ }^{[9]}$ hierarchically porous structures, ${ }^{\left[{ }^{[9]}\right.}$ and, especially, heterogeneous growth or assembly ${ }^{[10]}$ have achieved some successes in optimizing catalytic activity for in situ synthesis of $\mathrm{H}_{2} \mathrm{O}_{2}$ from $\mathrm{H}_{2}$ and $\mathrm{O}_{2}$. AuPd bimetals exhibit outstanding ability in catalytic hydrogenation to improve the yield and selectivity of $\mathrm{H}_{2} \mathrm{O}_{2}$ formation. It has been reported that the $\mathrm{Pd} / \mathrm{Au}(111)$ and $\mathrm{Pd} / \mathrm{Au}(100)$ nanocrystal surfaces have superior activity and are responsible for the generation of active atomic hydrogen, which contributes to the $\mathrm{H}_{2} \mathrm{O}_{2}$ synthesis. ${ }^{[11]}$ Moreover, the promotional effects of Au on AuPd nanocomposites have drawn attention. ${ }^{[12]}$ Carbon nanotubes (CNTs), as a carbonaceous material with high surface area, good conductivity, strong mechanical properties, and chemical stability, have been identified as promising substrates in the synthesis of nanocomposites. ${ }^{[13]}$ Recent studies demonstrate that catalysts (e.g., metals, transition-metal chalcogenides and oxides) supported on CNTs can notably accelerate the electrocatalytic behavior relative to those on conventional carbon-based supports. ${ }^{[14]}$ On the one hand, the functional nanoparticles can be encapsulated and dispersed inside/outside the CNTs, thereby contributing to the elevation of the catalytic performance of the nanocomposites. ${ }^{[15]}$ On the other hand, low-load nanocrystals on CNTs not only avoid the drawback of inactivation caused by particle agglomeration, but also the CNTs themselves play distinctive roles in the electrocatalytic activity. ${ }^{[16]}$ Therefore, the novel strategy of integrating AuPd nanocrystals with CNTs is a promising way to develop a highly catalytic, durable, and low-cost catalyst for in situ production of $\mathrm{H}_{2} \mathrm{O}_{2}$, and to achieve an efficient degradation of contaminants through the electrocatalytic EF process. However, little work has been done on directly synthesizing AuPd/CNTs for use as efficient electrocatalysts, and the role of $\mathrm{Au}$ nanocrystals on AuPd bimetallic nanocomposites in the catalytic generation of $\mathrm{H}_{2} \mathrm{O}_{2}$ is also poorly understood.

Herein, AuPd/CNT nanocomposites were directly synthesized through facile grain nucleation and heterogeneous crystal growth of AuPd on CNTs. X-ray diffraction (XRD), scanning electron microscopy (SEM), transmission electron microscopy (TEM), and X-ray photoelectron spectroscopy (XPS) were employed to characterize the AuPd/CNT nanocomposites. The results indicated that heterogeneous AuPd nanocrystals were well dispersed on the CNTs and the specific heterostructure of the catalysts engendered optimized catalytic characteristics in $\mathrm{H}_{2} \mathrm{O}_{2}$ synthesis. The effects of operating parameters including solution $\mathrm{pH}, \mathrm{Au}$ loading, current density, and initial contami- nant concentration were analyzed in the EF degradation of organic contaminants. The functional and structural aspects of the promoting role of Au on nanocomposites were elucidated. Finally, proposed mechanisms for the degradation pathway of pollutants and generation of reactive oxidizing species based on AuPd/CNTs were described.

\section{Results and Discussion}

\section{Characterization of AuPd/CNT nanocatalysts}

Figure 1 a shows the powder XRD patterns of CNTs and of $1 \%$ $\mathrm{Pd} / \mathrm{CNT}, 1 \% \mathrm{Au} / \mathrm{CNT}$, and $0.5 \% \mathrm{Au} 0.5 \% \mathrm{Pd} / \mathrm{CNT}$ nanocomposites. The as-prepared CNTs support bimetallic AuPd particles
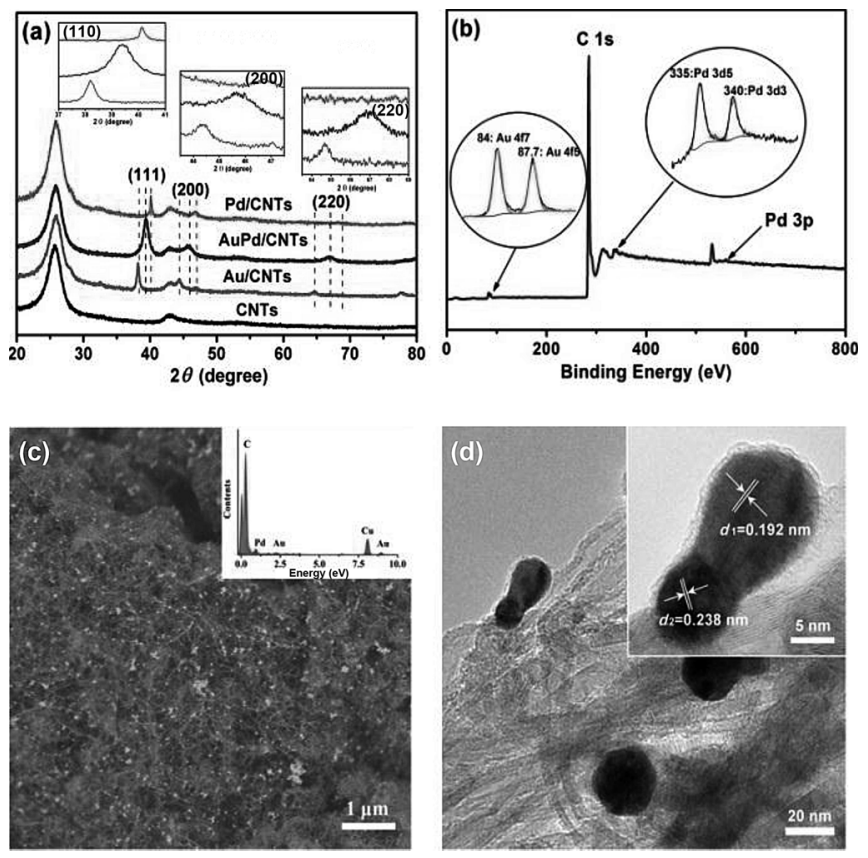

Figure 1. a) XRD patterns of CNTs, $1 \% \mathrm{Pd} / \mathrm{CNTs}, 1 \% \mathrm{Au} / \mathrm{CNTs}$, and $0.5 \% \mathrm{Au}$ $0.5 \% \mathrm{Pd} / \mathrm{CNTs}$. b) XPS spectra of $0.5 \% \mathrm{Au} 0.5 \% \mathrm{Pd} / \mathrm{CNT}$ nanocomposites. The insets show the high-resolution XPS patterns of Au and Pd. c) SEM image of AuPd/CNTs. The inset shows the corresponding energy-dispersive X-ray spectrum. d) TEM image of AuPd/CNTs. The inset shows the HRTEM image of heterogeneous AuPd nanocrystals on CNTs.

(AuPd/CNTs), and monometallic $\mathrm{Au}$ (Au/CNTs) and Pd (Pd/ CNTs). Typical diffraction peaks of CNTs can be observed at 26 and $42.9^{\circ}$ from all the synthesized nanocomposites. Strong peaks at $40.4,47.1$, and $68^{\circ}$ of $\mathrm{Pd} / \mathrm{CNTs}$ correspond well to the (111), (200), and (220) planes of Pd. Similarly, Au/CNTs also have typical diffraction peaks of monometallic Au at 38.3 and $44.2^{\circ}$, which suggests the exposure of $A u(111)$ and $A u(200)$ planes. Notably, three diffraction peaks located at 39.4, 45.6, and $67.1^{\circ}$ for bimetallic AuPd lie between the corresponding phase peak positions of pure $\mathrm{Au}$ and $\mathrm{Pd}$, thus indicating the successful formation of AuPd bimetals. ${ }^{[17,18]}$ Moreover, the AuPd/CNTs strengthen the crystal planes of alloys with strong diffraction peaks relative to $\mathrm{Au} / \mathrm{CNTs}$ and $\mathrm{Pd} / \mathrm{CNTs}$ under the 
same load of metal (1 wt \%), which suggests that the crystal planes of bimetals are strengthened and may prominently contribute to a greater potential electrocatalytic activity. The $0.5 \%$ $\mathrm{Au} 0.5 \% \mathrm{Pd} / \mathrm{CNT}$ nanocomposites were further characterized by XPS to confirm the elemental composition and metallic state. As can be seen from Figure $1 \mathrm{~b}$, only C 1s, Pd3d, Pd3p, and $A u 4 f$ can be found with their corresponding binding energies, without any impurity. High-resolution XPS spectra of $\mathrm{Pd} 3 \mathrm{~d}$ and Au4f peaks for the AuPd/CNT nanocomposites are shown as insets in Figure $1 \mathrm{~b}$. The binding energies of $\mathrm{Pd} 3 \mathrm{~d}$ at 335 and $340 \mathrm{eV}$ and of $\mathrm{Au} 4 \mathrm{f}$ at 84 and $87.7 \mathrm{eV}$ are well fitted to the signals of pure metallic elements.

The SEM image illustrates the good dispersion of AuPd nanoparticles supported on CNTs (Figure $1 \mathrm{c}$ ). The insight further reveals the purity of the nanocatalysts. The TEM image shows that the majority of spherical AuPd nanocrystals were synthesized with an approximate diameter of $20 \mathrm{~nm}$ stably dispersed on the surface of CNTs (see Figure $1 \mathrm{~d}$ ). A small fraction of some nanoparticles agglomerates together, with the result that some large particles with an approximate diameter of $50 \mathrm{~nm}$ are formed. Moreover, the heterogeneous growth of AuPd nanoparticles can be clearly observed from Figure $1 \mathrm{~d}$. The inset in Figure $1 \mathrm{~d}$ shows some details of heterostructured AuPd nanoparticles with well-defined crystalline lattices: a lattice spacing of $0.192 \mathrm{~nm}$ corresponding to the (111) plane of $\mathrm{Pd}(0.19 \mathrm{~nm})$; and a lattice at a different orientation with a spacing of $0.238 \mathrm{~nm}$, similar to $\mathrm{Au}(111)(0.24 \mathrm{~nm})$. Additional$l y$, the porous network and pore size distribution of the catalyst were measured by BET analysis (Figure S1 in the Supporting Information), which illustrates that the catalyst should favor the adsorption of $\mathrm{H}_{2}$ and $\mathrm{O}_{2}$ during the EF process.

\section{Au-enhanced performance in the electro-Fenton process}

\section{Degradation of organic contaminants}

Figure $2 \mathrm{a}$ illustrates the superior catalytic performance in the removal of dimethylacetamide (DMAC) based on AuPd/CNT nanocatalysts in the EF process. By comparison, in the presence of $1 \mathrm{~g} \mathrm{~L}^{-1} 1 \% \mathrm{Pd} / \mathrm{CNTS}$ alone, there was only slight degradation of DMAC, which suggests inefficient adsorption of DMAC on Pd/CNTs. However, nearly $20 \%$ removal of DMAC within 60 min was attained only by electrolysis, thus implying that the removal of DMAC by a dimensionally stable anode (DSA) is also limited. In contrast, integration of $1 \mathrm{~g} \mathrm{~L}^{-1} \mathrm{Pd} / \mathrm{CNTS}$ with electrolysis contributed to the degradation of DMAC, which can be possibly ascribed to oxidation by active radicals caused by catalytic reaction of generated $\mathrm{H}_{2} \mathrm{O}_{2}$ on the DSA or $\mathrm{Pd} / \mathrm{CNT}$ cathodes. Furthermore, the addition of $\mathrm{Fe}^{2+}$ markedly elevated the removal efficiency of DMAC in the presence of nanocatalysts under electrolysis. For example, DMAC was totally mineralized within $50 \mathrm{~min}$ by Pd/CNTs, and $100 \%$ DMAC was thoroughly degraded within $37 \mathrm{~min}$ by the $0.5 \% \mathrm{Au} 0.5 \% \mathrm{Pd} /$ CNTs catalytic EF process under a current density of $50 \mathrm{~mA} \mathrm{~cm}^{-2}, 1 \mathrm{~g} \mathrm{~L}^{-1}$ catalyst, initial $\mathrm{pH} \mathrm{3}$, and $100 \mathrm{mg} \mathrm{L}^{-1}$ DMAC. It is evident that the introduction of $A u$ enhances the catalytic degradation of DMAC, and the performance of the AuPd/CNTs catalytic EF process is significantly superior to that reported in some similar studies. $\left.{ }^{[5, \mathrm{~d}]}\right]$ The degradation of DMAC by the catalytic EF process approximately followed pseudo-first-order kinetics owing to the stable synthesis of ${ }^{\circ} \mathrm{OH}$ radicals. ${ }^{[3,6]}$ Hence, the pseudo-first-order rate constants can be calculated as $0.030 \mathrm{~min}^{-1}\left(R^{2}=0.995\right)$ for $\mathrm{Pd} / \mathrm{CNTS}$ and $0.051 \mathrm{~min}^{-1}\left(R^{2}=\right.$ 0.986) for AuPd/CNTs. The obtained $k$ value based on AuPd/
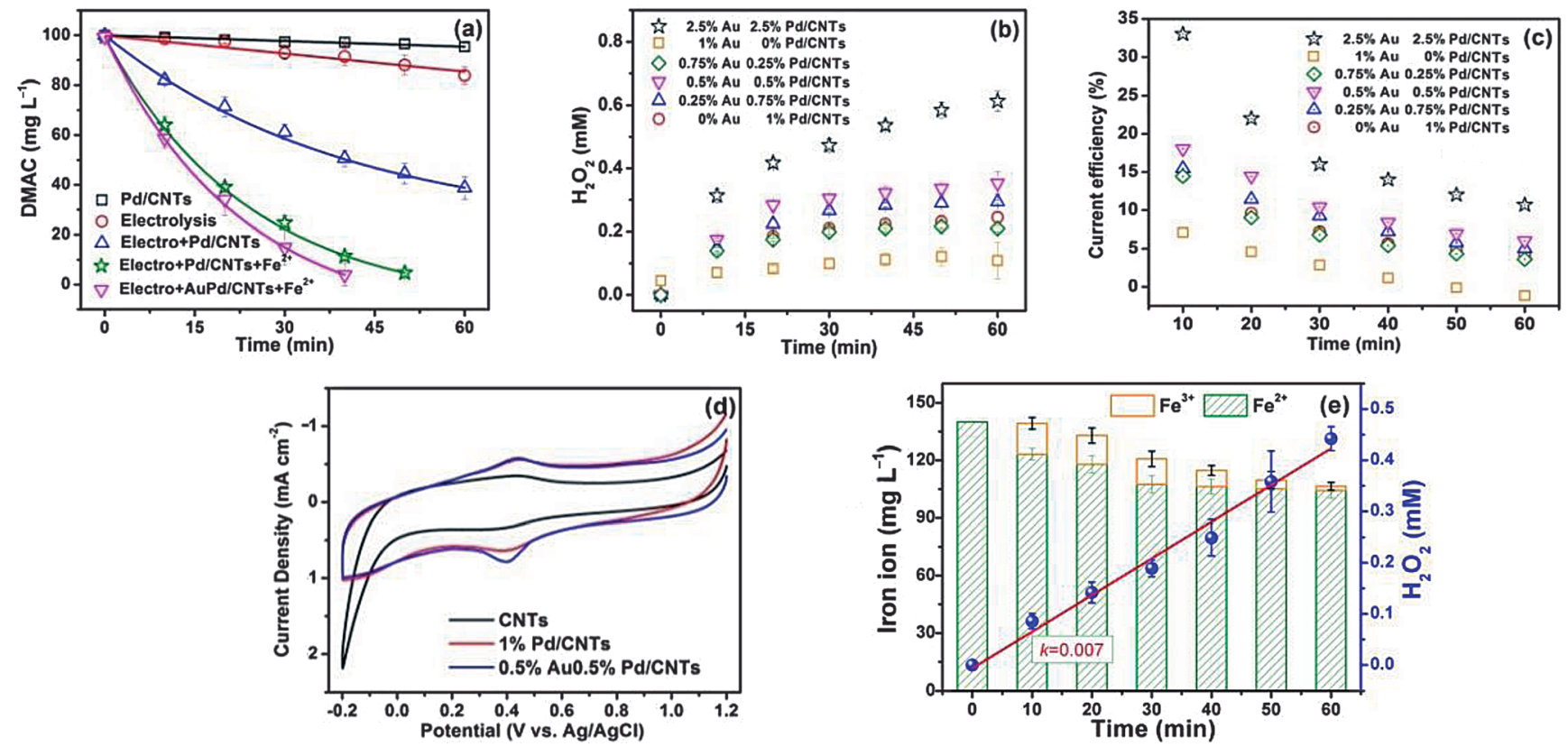

Figure 2. a) Degradation of DMAC under different conditions. b, c) Effects of Au loading on AuPd/CNTs on b) $\mathrm{H}_{2} \mathrm{O}_{2}$ generation and c) current efficiency; $1 \mathrm{gL} \mathrm{L}^{-1}$ catalyst: Au loading from 0 to $1 \%$ in AuPd/CNTs (balance Pd for $1 \%$ metal total), and $2.5 \%$ Au $2.5 \%$ Pd/CNTs. d) Cyclic voltammograms of CNTs, Pd/CNTs, and AuPd/CNTs in $\mathrm{H}_{2}$ - and $\mathrm{O}_{2}$-saturated acidic solutions. Scan rate: $50 \mathrm{mV} \mathrm{s}^{-1}$. e) Simultaneous changes of $\mathrm{H}_{2} \mathrm{O}_{2}, \mathrm{Fe}^{2+}$, and Fe ${ }^{3+}$ during the $\mathrm{EF}$ process in the presence of $1 \mathrm{~g} \mathrm{~L}^{-1} 0.5 \% \mathrm{Au} 0.5 \% \mathrm{Pd} / \mathrm{CNTs}$. Unless otherwise specified, the reaction conditions were based on $1 \mathrm{gL}^{-1} \mathrm{catalyst}(0.5 \% \mathrm{Au} 0.5 \% \mathrm{Pd} / \mathrm{CNTs}$ and $1 \% \mathrm{Pd} /$ CNTs), initial $\mathrm{pH} 3,50 \mathrm{mAcm}^{-2}, 100 \mathrm{mg} \mathrm{L}^{-1} \mathrm{DMAC}$, and $2.5 \mathrm{~mm} \mathrm{Fe}^{2+}$. 
CNTs is greater than those reported by Luo et al. $\left(0.033 \mathrm{~min}^{-1}\right)$ and Zhao et al. $\left(0.016 \mathrm{~min}^{-1}\right)$ in similar catalytic systems. ${ }^{[5 a, b, 19]}$ Moreover, although the normalized concentration of AuPd on the AuPd/CNTs $\left(0.01 \mathrm{~g} \mathrm{AuPdL}^{-1}\right)$ is one order of magnitude smaller than the concentration of $\mathrm{Pd}\left(0.125 \mathrm{~g} \mathrm{PdL}^{-1}\right)$ used in the reported $\mathrm{Pd} / \mathrm{C}$ catalytic EF process, the comparable $k$ value achieved by the AuPd/CNTs catalytic EF process further highlighted its unexpectedly high catalytic capacity for such low loading of AuPd. ${ }^{[5 d]}$ Therefore, it can be concluded that $0.5 \%$ $\mathrm{Au} 0.5 \% \mathrm{Pd} / \mathrm{CNTs}$ have superior performance in DMAC removal during the catalytic EF process compared with $1 \% \mathrm{Pd} / \mathrm{CNTS}$ and some similar Pd-based catalysts. Clearly, the introduction of $\mathrm{Au}$ on AuPd/CNTs seems to play a crucial role in the catalytic capacity for organic contaminant removal.

\section{In situ synthesis of $\mathrm{H}_{2} \mathrm{O}_{2}$}

As can be seen from Figure $2 \mathrm{~b}$, different loadings of AuPd on CNTs have varied efficiency in the catalytic synthesis of $\mathrm{H}_{2} \mathrm{O}_{2}$ only in electrolysis without $\mathrm{Fe}^{2+}$. On comparing 1 and $5 \mathrm{wt} \%$ loading of alloys on AuPd/CNTs, a higher quantity of alloy resulted in a higher concentration of $\mathrm{H}_{2} \mathrm{O}_{2}$. However, $\mathrm{H}_{2} \mathrm{O}_{2}$ synthesis did not scale linearly with the proportion of bimetallic loading, which can be ascribed to the catalytic decomposition of $\mathrm{H}_{2} \mathrm{O}_{2}$ caused by exposure of surplus active sites over the AuPd surface [Eq. (6)]. ${ }^{[6]}$ The optimal in situ synthesis of $\mathrm{H}_{2} \mathrm{O}_{2}$ from $0.5 \% \mathrm{Au} 0.5 \% \mathrm{Pd} / \mathrm{CNTs}$ was nearly $0.30 \mathrm{~mm}$ within 20 min. In sharp contrast, just $0.19 \mathrm{~mm}$ was obtained for $1 \%$ $\mathrm{Pd} / \mathrm{CNTs}$, and only $0.04 \mathrm{~mm}$ for $1 \% \mathrm{Au} / \mathrm{CNTs}$. The results indicate an advantage in $\mathrm{H}_{2} \mathrm{O}_{2}$ synthesis by AuPd/CNTs compared with catalytic synthesis of $\mathrm{H}_{2} \mathrm{O}_{2}$ by $\mathrm{Au} / \mathrm{CNTS}$ alone. However, the concentration of $\mathrm{H}_{2} \mathrm{O}_{2}$ increased with the increase of $\mathrm{Au}$ loading from 0.25 to $0.50 \%$ on AuPd/CNTs, further suggesting the promoting role of $\mathrm{Au}$ for $\mathrm{H}_{2} \mathrm{O}_{2}$ synthesis. Moreover, with the further increase of Au loading to $0.75 \%$, a slight decrease was observed after $20 \mathrm{~min}$. Therefore, an appropriate Au loading on $\mathrm{AuPd} / \mathrm{CNTS}$ is beneficial for optimizing synthesis of $\mathrm{H}_{2} \mathrm{O}_{2}$.

$\mathrm{H}_{2} \mathrm{O}_{2} \stackrel{\mathrm{Pd}}{\longrightarrow} 2 \mathrm{HO}^{\bullet}$

In addition, the current efficiency (CE) for different loadings of $\mathrm{Au}$ on AuPd/CNTs was investigated. A gradual decay of CE with time was observed as shown in Figure $2 \mathrm{c}$. In particular, the highest CE of nearly $35 \%$ was obtained by $2.5 \%$ Au $2.5 \%$ $\mathrm{Pd} / \mathrm{CNTS}$ at the beginning of the electrolysis with $50 \mathrm{mAcm}^{-2}$, which is close to the previously reported value. ${ }^{[5 \mathrm{~d}]}$ As expected, the CE gradually decreased with the process of electrolysis. The $0.5 \%$ Au $0.5 \%$ Pd/CNTs still had the highest CE of $6.1 \%$ at 60 min compared with the same loading of $1 \%$ AuPd bimetals. Thus, the functional role of the appropriate Au loading in accelerating the transport of electrons over the surface of nanocatalysts is further confirmed, thereby demonstrating its effectiveness in the direct synthesis of $\mathrm{H}_{2} \mathrm{O}_{2}$ from $\mathrm{H}_{2}$ and $\mathrm{O}_{2}$ released by water electrolysis. ${ }^{[20]}$

To investigate the synthesis of $\mathrm{H}_{2} \mathrm{O}_{2}$ over different nanocatalysts in more depth, the cyclic voltammograms of CNTs, $1 \%$
$\mathrm{Pd} / \mathrm{CNTs}$, and $0.5 \% \mathrm{Au} 0.5 \% \mathrm{Pd} / \mathrm{CNTs}$ in $\mathrm{H}_{2}$ - and $\mathrm{O}_{2}$-saturated acidic solution were evaluated. As shown in Figure $2 \mathrm{~d}$, a broad flat curve of CNTs was observed in the potential range from 0 to $1.2 \mathrm{~V}$, and the peak of $\mathrm{H}_{2}$ evolution appeared at 0 to $-0.2 \mathrm{~V}$. As for Pd/CNTs and AuPd/CNTs, the response current increased significantly, and the peak at $0.4 \mathrm{~V}$ corresponding to the oxygen reduction reaction (ORR) could be found for both nanocatalysts in $\mathrm{O}_{2}$-enriched solution, ${ }^{[21]}$ which verified their electrocatalytic activity for $\mathrm{H}_{2} \mathrm{O}_{2}$ synthesis. In contrast, the limiting current density of AuPd/CNTs for ORR electrocatalysis was $0.78 \mathrm{~mA} \mathrm{~cm}^{-2}$, whereas that for Pd/CNTs was just $0.60 \mathrm{~mA} \mathrm{~cm}^{-2}$, which demonstrated that AuPd/CNTs have enhanced catalytic performance for $\mathrm{H}_{2} \mathrm{O}_{2}$ synthesis compared with $\mathrm{Pd} / \mathrm{CNTs}$ and bare CNTs. The promoting function of Au loading on AuPd/ CNTs was again confirmed. As reported, ${ }^{[22]}$ a two-step reaction mechanism of $\mathrm{H}_{2} \mathrm{O}_{2}$ synthesis is widely accepted, starting from the dissociation of $\mathrm{O}_{2}$ [Eq. (7)] on the Pd surface and a subsequent two hydrogen atom [Eqs. (8) and (9)] combination. However, an undesirable pathway of dioxygen dissociation always leads to the nonselective formation of $\mathrm{H}_{2} \mathrm{O}$ [Eq. (10)], which is detrimental for $\mathrm{H}_{2} \mathrm{O}_{2}$ generation. The presence of surface $\mathrm{Au}$ atoms blocks this dissociation and increases the selectivity toward $\mathrm{H}_{2} \mathrm{O}_{2}$ [Eq. (11)]. Therefore, appropriate loading of $\mathrm{Au}$ on AuPd/CNTs notably increases the $\mathrm{H}_{2} \mathrm{O}_{2}$ formation rate, and the optimized ratio of $\mathrm{Au}$ and $\mathrm{Pd}$ significantly improves the catalytic selectivity and reduces the activation energy of the $\mathrm{H}_{2} \mathrm{O}_{2}$ synthesis reaction.

$$
\begin{aligned}
& \mathrm{O}_{2} \stackrel{\text { Pdsurface }}{\longrightarrow} \mathrm{O}^{\bullet}+\mathrm{O}^{\bullet} \\
& \mathrm{O}_{2}+\mathrm{H}^{\bullet} \stackrel{\text { Pdsurface }}{\longrightarrow} \mathrm{OOH}^{\bullet} \\
& \mathrm{OOH}^{\bullet}+\mathrm{H}^{\bullet} \stackrel{\text { Pdsurface }}{\longrightarrow} \mathrm{H}_{2} \mathrm{O}_{2} \\
& \mathrm{OOH}^{\bullet}+\mathrm{H}^{\bullet} \stackrel{\text { Pdsurface }}{\longrightarrow} \mathrm{H}_{2} \mathrm{O}+\mathrm{O}^{\bullet} \\
& \mathrm{OOH}^{\bullet}+\mathrm{H}^{\bullet} \stackrel{\text { AuPdsurface }}{\longrightarrow} \mathrm{H}_{2} \mathrm{O}_{2}
\end{aligned}
$$

\section{In situ regeneration of $\mathrm{Fe}^{2+}$}

A certain amount of added $\mathrm{Fe}^{2+}\left(140 \mathrm{mg} \mathrm{L}^{-1}\right)$ at initial $\mathrm{pH} 3$ could homogeneously catalyze the decomposition of $\mathrm{H}_{2} \mathrm{O}_{2}$ into $\mathrm{OH}$ radicals. To further reveal the contribution of iron species and accumulation of $\mathrm{H}_{2} \mathrm{O}_{2}$ during the catalytic electrolysis, dissolved concentrations of $\mathrm{Fe}^{2+}, \mathrm{Fe}^{3+}$, and $\mathrm{H}_{2} \mathrm{O}_{2}$ were monitored during electrolysis (Figure 2e). The total dissolved Fe species gradually decreased from 140 to $104 \mathrm{mg} \mathrm{L}^{-1}$, which indicated that sedimentation of $\mathrm{Fe}$ was inevitable. Dissolved $\mathrm{Fe}^{2+}$ was distinctly dominant among the dissolved species (Figure S2 in the Supporting Information). The proportion of $\mathrm{Fe}^{2+}$ in the total dissolved Fe species increased from 88.6 to $98.1 \%$, which demonstrates a continuous accumulation of dissolved $\mathrm{Fe}^{2+}$ through the pathway of $\mathrm{Fe}^{3+}$ reduction. The slight change in $\mathrm{Fe}^{2+}$ concentration suggests that homogeneous catalysis by dissolved $\mathrm{Fe}^{2+}$ is significant and in situ regeneration of $\mathrm{Fe}^{2+}$ in the AuPd/CNTs catalytic EF process is also effective. Notably, acidic Fenton chain reactions generally result in a final accumulation of $\mathrm{Fe}^{3+}$ due to the relatively high reaction rate con- 
stants indicated in Equations (12) and (13). ${ }^{[4]}$ However, in this $\mathrm{AuPd} / \mathrm{CNTS}$ catalytic EF system, the in situ transformation of $\mathrm{Fe}^{3+}$ to $\mathrm{Fe}^{2+}$ promoted by $\mathrm{H}$ atoms released from the surface of nanocatalysts is of great importance. Actually, the reducing action of the $\mathrm{H}$ atom is enhanced by the AuPd/CNTs catalytic system, which finally leads to a distinct reaction environment compared with the initial conditions: only $2.12 \mathrm{mg} \mathrm{L}^{-1} \mathrm{Fe}^{3+}$ was left within $60 \mathrm{~min}$. Meanwhile, under the intensive regeneration of $\mathrm{Fe}^{2+}$, the strong generation of $\mathrm{H}_{2} \mathrm{O}_{2}$ resulted in approximately linear growth of $\mathrm{H}_{2} \mathrm{O}_{2}$, which followed zerothorder kinetics (see straight line in Figure $2 \mathrm{e}, k=0.007$ ). ${ }^{[6]}$ As seen from Figure $2 \mathrm{e}$, although the mole ratio of $\mathrm{Fe}^{2+}$ to $\mathrm{H}_{2} \mathrm{O}_{2}$ declined from 24.01 to 4.13 in $60 \mathrm{~min}$, this is still much higher than the optimal value (1.0 to 0.2 ) accepted for the EF process. ${ }^{[23]}$ In other words, the initial $\mathrm{Fe}^{2+}$ dosage of $2.5 \mathrm{~mm}$ used here, which was also widely adopted in similar studies, ${ }^{\left[{ }^{[a, d]}\right.}$ was superfluous. As a result, the advantageous regeneration of $\mathrm{Fe}^{2+}$ in the AuPd/CNTs catalytic EF process is critical to decrease the initial dosage requirement for $\mathrm{Fe}^{2+}$.

$$
\begin{aligned}
& \mathrm{Fe}^{2+}+\mathrm{HO}^{\cdot} \rightarrow \mathrm{Fe}^{3+}+\mathrm{HO}^{-} \quad k_{2}=3.2 \times 10^{8} \mathrm{M}^{-1} \mathrm{~s}^{-1} \\
& \mathrm{Fe}^{3+}+\mathrm{HO}_{2}^{\cdot} \rightarrow \mathrm{Fe}^{2+}+\mathrm{O}_{2}+\mathrm{H}^{+} \quad k_{2}=2 \times 10^{3} \mathrm{M}^{-1} \mathrm{~s}^{-1}
\end{aligned}
$$

\section{Effects of initial pH, current density, $\mathrm{Fe}^{2+}$ dosage, and DMAC concentration on DMAC degradation}

As mentioned above, it was found that the AuPd/CNTs catalytic EF process had excellent advantages compared with some previous studies focused on the Pd-based catalytic EF process, ${ }^{[5 a, b]}$ such as superior effectiveness in the synthesis of $\mathrm{H}_{2} \mathrm{O}_{2}$, regeneration of $\mathrm{Fe}^{2+}$, and removal of organic pollutants. On this basis, the effects of $\mathrm{pH}$, current density, initial $\mathrm{Fe}^{2+}$ dosage, and initial DMAC concentration on the degradation of DMAC were further investigated to optimize the AuPd/CNTs catalytic EF process. Initial solution $\mathrm{pH}$ plays a vital role in the EF process. ${ }^{[24]}$ Figure 3 a illustrates the effects of initial solution $\mathrm{pH}$ on DMAC degradation. With an initial $\mathrm{pH}$ higher than 6 there is scarcely any removal of DMAC within 60 min of treatment, which indicates that near-neutral $\mathrm{pH}$ conditions are undesirable for the formation of $\mathrm{H}_{2} \mathrm{O}_{2}$. On decreasing the $\mathrm{pH}$ from 5 to 3, the highest pseudo-first-order kinetic constant of DMAC removal was attained at $\mathrm{pH} 3\left(k_{1}=0.24\right)$, further suggesting that the optimal $\mathrm{pH} 3$ not only contributes to the optimization of the $\mathrm{EF}$ reaction, but also benefits the generation and stabilization of $\mathrm{H}_{2} \mathrm{O}_{2}$. However, when the $\mathrm{pH}$ drops to 2, the removal of DMAC only reaches $79 \%$ at $60 \mathrm{~min}$. It is reasonable that an overly acidic condition $(\mathrm{pH} \leq 2)$ leads to excessive dissolution of $\mathrm{Fe}^{2+}$ from the cathode, which can accelerate the competitive combination with ${ }^{\circ} \mathrm{OH}$ radicals [Eq. (2)] ${ }^{[25]}$ and reduces the utilization of ${ }^{\circ} \mathrm{OH}$ in DMAC removal. Additionally, strong acidity might destroy the heterostructure of the AuPd nanocrystals. Therefore, the optimal initial solution $\mathrm{pH}$ is 3 . Applied current density is employed as the main driving force for the release of $\mathrm{H}_{2}$ and $\mathrm{O}_{2}$ from the electrodes under electrolysis. As a result, the degradation of DMAC increases with increasing current density (Figure $3 \mathrm{~b}$ ). Current densities of 12.5, 25, and
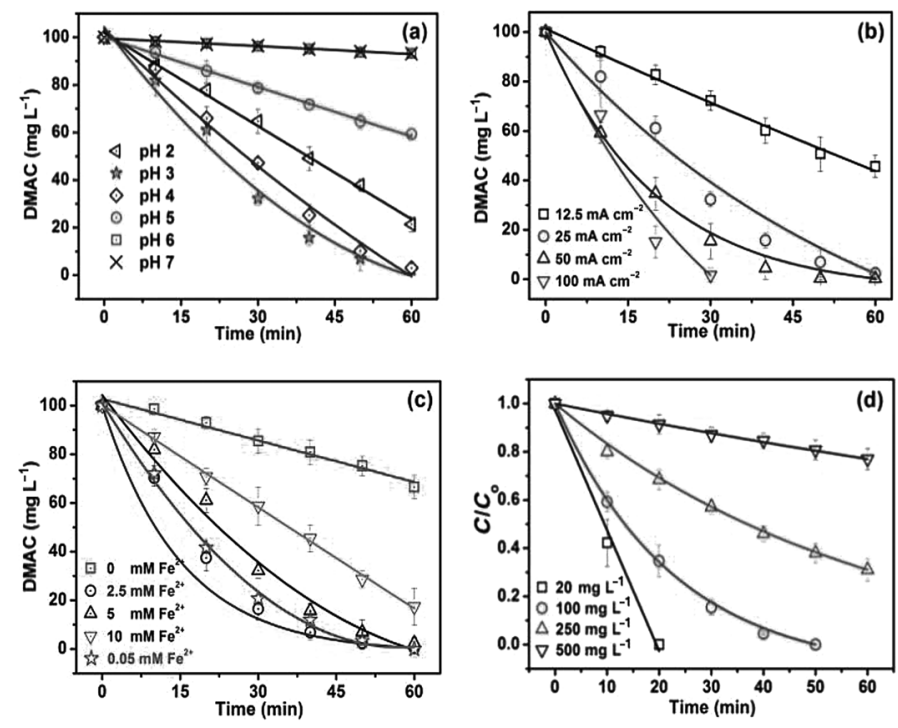

Figure 3. Effects of a) initial $\mathrm{pH}, \mathrm{b}$ ) current density, c) initial $\mathrm{Fe}^{2+}$ dosage, and d) initial DMAC concentration on DMAC degradation. $C_{0}$ represents initial DMAC concentration; $C$ is the concentration of DMAC with time. Unless otherwise specified, the reaction conditions were based on $1 \mathrm{~g} \mathrm{~L}^{-1}$ AuPd/CNTs (0.5 wt \% Au, 0.5 wt \% Pd), initial $\mathrm{pH} 3,50 \mathrm{mAcm}^{-2}$, and $100 \mathrm{mg} \mathrm{L}^{-1}$ initial DMAC concentration.

$50 \mathrm{~mA} \mathrm{~cm}^{-2}$ exhibited considerably different performance in the degradation of DMAC, with corresponding kinetic constants of $0.0014,0.017$, and $0.049 \mathrm{~min}^{-1}$, respectively, whereas with a current density of $100 \mathrm{mAcm}^{-2}$, superior removal efficiency was observed. A $100 \mathrm{mg} \mathrm{L}^{-1}$ concentration of DMAC was absolutely destroyed within $30 \mathrm{~min}$, which is mainly ascribed to the anodic oxidation of DMAC. Actually, as current density increases, some negative factors, including concentration polarization and anodic cleanout of $\mathrm{H}_{2} \mathrm{O}_{2}$, cannot be ignored. ${ }^{[26]}$ Thus, the best current density is $50 \mathrm{mAcm}^{-2}$. The initial dosage of $\mathrm{Fe}^{2+}$ determines the catalytic efficiency of the $\mathrm{EF}$ process and the decay of DMAC. As shown in Figure $3 c$, more than $85 \%$ DMAC still remained after 60 min without addition of $\mathrm{Fe}^{2+}$. As the $\mathrm{Fe}^{2+}$ dosage increases from 2.5 to $10 \mathrm{~mm}$, a distinct decline of DMAC can be observed $\left(k_{1}\right.$ reduces from 0.066 to $\left.0.0003 \mathrm{~min}^{-1}\right)$. As mentioned before, large amounts of $\mathrm{Fe}^{2+}$ damage the startup of the $\mathrm{EF}$ process and cause a poor ratio of $\mathrm{Fe}^{2+} / \mathrm{H}_{2} \mathrm{O}_{2}$. Furthermore, the in situ regeneration of $\mathrm{Fe}^{2+}$ by active $\mathrm{H}$ atoms released from the AuPd/CNTs catalytic process is potent. ${ }^{[27]}$ On this basis, a $0.05 \mathrm{~mm}$ initial dosage of $\mathrm{Fe}^{2+}$ (the tested concentration is much lower than those reported befo$\left.\mathrm{re}^{[5 \mathrm{a}, \mathrm{d}]}\right)$ was evaluated, and the results demonstrated that $0.05 \mathrm{~mm}$ of $\mathrm{Fe}^{2+}$ can also adequately initiate the AuPd/CNTs catalytic EF process and perform as well as $2.5 \mathrm{~mm} \mathrm{Fe}{ }^{2+}$. The remarkable removal efficiency of DMAC under $0.05 \mathrm{~mm}$ of $\mathrm{Fe}^{2+}$ within 60 min was $95.16 \%$, further revealing the intensive in situ regeneration of $\mathrm{Fe}^{2+}$ based on AuPd/CNT nanocatalysts. Because of the requirement of a low level of $\mathrm{Fe}^{2+}$ in the AuPd/ CNTs catalytic EF process, $0.05 \mathrm{~mm} \mathrm{Fe} \mathrm{Fe}^{2+}$ for initiating the EF process is sufficient, which suggests great potential cost savings at the engineering scale. Various initial concentrations of DMAC ( 20 to $500 \mathrm{mg} \mathrm{L}^{-1}$ ) were used to evaluate the degrada- 
tion capacity of the AuPd/CNTs catalytic EF process. Figure $3 \mathrm{~d}$ illustrates that the decay of different initial concentrations of DMAC was well fitted by pseudo-first-order kinetics. The obtained kinetic constants decreased with increasing initial DMAC concentration, which was mainly due to the limited production of ${ }^{\circ} \mathrm{OH}$ radicals released from the AuPd/CNTs catalytic EF process. The optimal concentration of DMAC chosen at $100 \mathrm{mgL}^{-1}$ is reasonable for full catalytic degradation under the conditions of $0.5 \% \mathrm{Au} \quad 0.5 \% \mathrm{Pd} / \mathrm{CNT}$ nanocatalysts, $50 \mathrm{~mA} \mathrm{~cm}^{-2}$, and initial $\mathrm{pH} 3$.

\section{The catalytic characteristics of AuPd/CNT nanocatalysts}

The Au loaded on AuPd/CNT nanocatalysts enhanced their performance relative to that of $\mathrm{Pd} / \mathrm{CNT}$ nanocatalysts in many aspects, giving a much higher level of $\mathrm{H}_{2} \mathrm{O}_{2}$ synthesis, higher-efficiency regeneration of $\mathrm{Fe}^{2+}$, and more complete degradation of organic pollutants. The characteristics of AuPd/CNTs were further investigated by XRD and XPS analysis. Figure 4 shows the XRD patterns of $1 \% \mathrm{Pd} / \mathrm{CNT}$ and $0.5 \% \mathrm{Au} 0.5 \% \mathrm{Pd} / \mathrm{CNTs}$ before and after catalysis under different exposure levels of $\mathrm{Fe}^{2+}$. As can be seen from Figure $4 \mathrm{a}$, the characteristic peaks of $1 \% \mathrm{Pd} / \mathrm{CNTs}$ at $2 \theta=40.4$ and $47.1^{\circ}$ were observed before catalysis. However, clear decay of Pd peaks was found after catalysis in the presence of 0.05 and $2.5 \mathrm{mM} \mathrm{Fe}^{2+}$. To verify the promoting role of $\mathrm{Au}$ in structural stabilization of AuPd/CNT nanocrystals during the catalytic EF process, the harsh $\mathrm{Fe}^{2+}$ condition of $2.5 \mathrm{~mm}$ was evaluated. In sharp contrast with $\mathrm{Pd} /$ CNTs, strong diffraction peaks at 38,44 , and $66^{\circ}$ were precisely matched with standards of pure AuPd before and after the catalysis (Figure 4 b). It was further revealed that the Au on AuPd/ CNTs changes the nanostructure of heterogeneous AuPd nanocrystals. Specifically, Au rearranges the AuPd alloy to expose the active $\mathrm{Pd}(111)$ crystal plane, ${ }^{[11]}$ which was also confirmed from the high-resolution transmission electron microscopy (HRTEM) images. Moreover, the slight modification of crystalline structure originating from the introduction of $\mathrm{Au}$ might contribute greatly to the electrocatalytic activity of AuPd/CNTs.

CNT substrates also make a significant contribution to the stabilization of the crystalline structure of AuPd/CNTs. On the one hand, the compact three-dimensional spatial structures built by the stacked nanotubes enhance the stability of the total spatial structure of AuPd/CNT nanocomposites. On the other hand, this framework network structure is beneficial to ensure homogenization and transport between the reactants and AuPd nanocrystals. In particular, as can be observed from Figure S3 in the Supporting Information, AuPd nanocrystals are stably embedded in the spatial structure built by CNTs after high catalytic EF performance, which further demonstrates that the well-structured AuPd nanocrystals are protected by the spatial network, and the deactivation observed for synthesized nanocatalysts caused by the agglomeration of nanoparticles is avoided with AuPd nanocrystals. As such, the leaching of AuPd was largely prevented. Additionally, Figure $4 \mathrm{c}$ and $4 \mathrm{~d}$ illustrate the different elemental composition and metallic state of $\mathrm{Pd} /$ CNTs and AuPd/CNTs before and after catalysis, respectively. Notably, peaks of Fe $2 p$ and Fe $3 p$ can be seen with their corre-
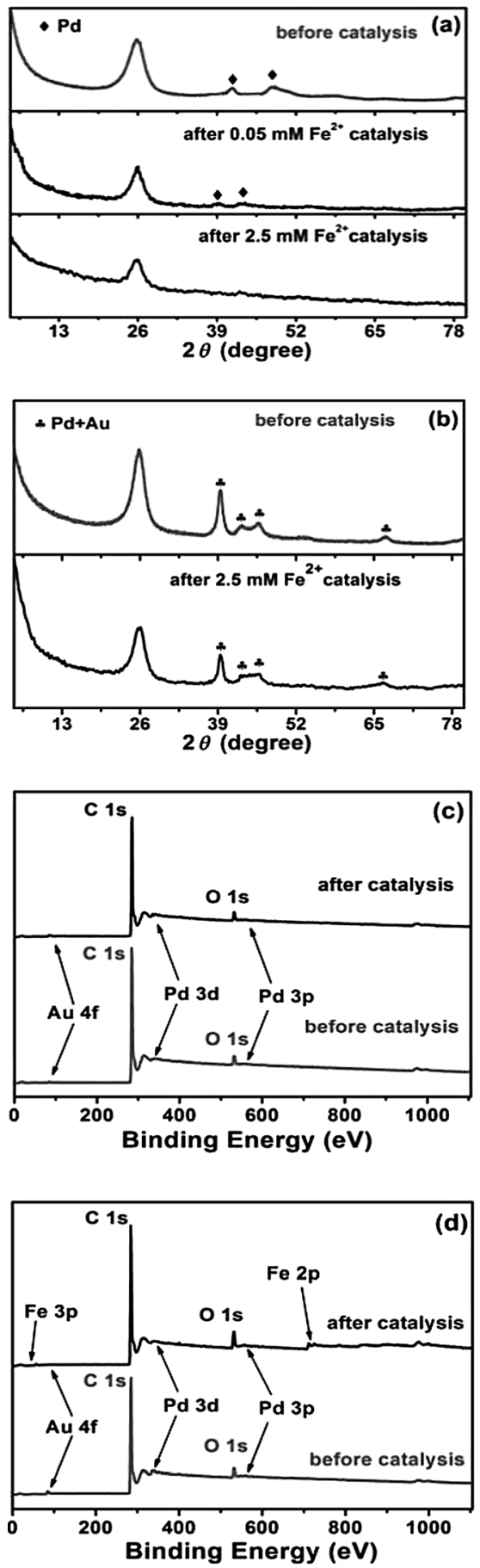

Figure 4. a) XRD patterns of $1 \% \mathrm{Pd} / \mathrm{CNTs}$ before and after $0.05 \mathrm{~mm} \mathrm{Fe}{ }^{2+}$ catalysis, and after $2.5 \mathrm{~mm} \mathrm{Fe}{ }^{2+}$ catalysis. b) XRD patterns of $0.5 \% \mathrm{Au} 0.5 \% \mathrm{Pd} /$ CNTs before and after $2.5 \mathrm{~mm} \mathrm{Fe}{ }^{2+}$ catalysis. c) XPS spectra of $1 \% \mathrm{Pd} / \mathrm{CNTs}$ before and after $2.5 \mathrm{~mm} \mathrm{Fe}^{2+}$ catalysis. d) XPS spectra of $0.5 \% \mathrm{Au} 0.5 \% \mathrm{Pd} /$ CNTs before and after $2.5 \mathrm{~mm} \mathrm{Fe}{ }^{2+}$ catalysis. Unless otherwise specified, the reaction conditions were based on $1 \mathrm{~g} \mathrm{~L}^{-1}$ catalysts, initial $\mathrm{pH} 3$, and $50 \mathrm{~mA} \mathrm{~cm}^{-2}$

sponding binding energies after the $\mathrm{Fe}^{2+}$ catalysis, thus revealing the deposition of Fe species on AuPd/CNTs. Specifically, characteristic peaks at 711,719 , and $724 \mathrm{eV}$ represent the binding energies of $\mathrm{Fe} 2 \mathrm{p}_{3 / 2}$, shake-up satellite of $\mathrm{Fe} 2 \mathrm{p}_{3 / 2}$, and Fe $2 p_{1 / 2}$ (Figure $S 5$ in the Supporting Information), which sug- 
gest the possible composition of Fe-containing substances supported on CNTs. It can be concluded that the introduction of Au on AuPd/CNTs leads to distinctive catalytic characteristics in several aspects, such as excellent structural stability of AuPd nanocrystals, protection of the crystalline structure by CNTs, and synergetic combination with Fe-containing substances on CNTs.

\section{Catalytic stability of AuPd/CNTs for repeated degradation}

As mentioned above, $\mathrm{Au}$ introduces superior catalytic characteristics to AuPd/CNTs, and the catalytic capacity of AuPd/CNTs over ten cycles of degradation of different organic pollutants (using DMAC and phenol as probes) was evaluated. The used AuPd/CNTs were separated from the solution by filtration, and then the washed and dried nanocatalysts were dropped into the reloaded contaminated solution again. Figure 5 illustrates

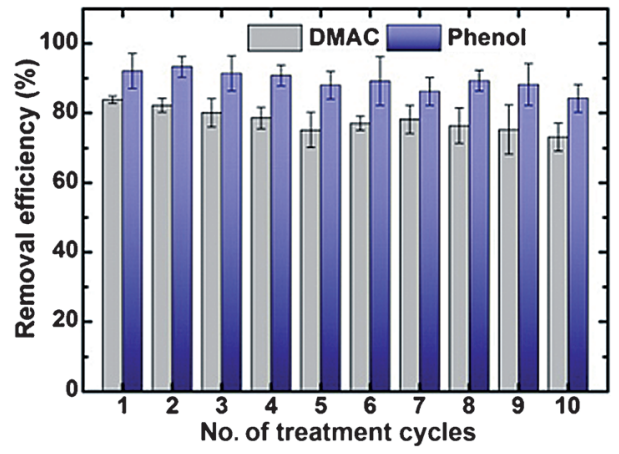

Figure 5. Changes of removal efficiency of DMAC and phenol as a function of treatment cycle. Each treatment was carried out with $2.5 \mathrm{~mm} \mathrm{Fe}{ }^{2+}, 1 \mathrm{~g} \mathrm{~L}^{-1}$ catalyst ( $0.5 \% \mathrm{Au} 0.5 \% \mathrm{Pd} / \mathrm{CNTs})$, initial $\mathrm{pH} 3,50 \mathrm{mAcm}^{-2}$, and $100 \mathrm{mg} \mathrm{L}^{-1}$ DMAC or phenol with 40 min of electrolysis.

that the removal efficiency of DMAC and phenol can be steadily maintained at nearly $80 \%$ and more than $90 \%$, respectively, thus demonstrating a desirable level of catalytic stability for AuPd/CNTs. Moreover, SEM images of AuPd/CNTs after ten utilization cycles show that there is no obvious aggregation of AuPd/CNT nanocomposites (Figure S6 in the Supporting Information). Therefore, AuPd/CNTs have good potential for sustainable recycling in the EF process.

\section{Proposed mechanisms of organic pollutant degradation based on AuPd/CNTs}

The proposed mechanism of the degradation of organic pollutants based on the AuPd/CNTs catalytic EF process was inferred according to the scavenging of ${ }^{\circ} \mathrm{OH}$ radicals by tert-butyl alcohol (TBA) and ESR assay. Degradation of phenol was clearly inhibited by the addition of TBA, with the kinetic constant dropping from 0.022 to $0.005 \mathrm{~min}^{-1}$ (Figure S7 in the Supporting Information). As seen from Figure $6 \mathrm{a}$, characteristic ESR signals of ${ }^{\circ} \mathrm{OH}$ were observed on the addition of AuPd/CNTs and $\mathrm{Fe}^{2+}$ under $30 \mathrm{~min}$ of electrolysis, thus validating the great contribution of ${ }^{\circ} \mathrm{OH}$ to the removal of organic pollutants. Furthermore, the signals intensified with the increasing loading of AuPd on CNTs (from 1 to 5 wt \%). However, AuPd/CNTs without $\mathrm{Fe}^{2+}$ in the electrolytic system resulted in no signal in response to $\mathrm{OH}$. The proposed mechanism in the AuPd/CNTs catalytic EF process is shown in Scheme 1. The main contribution to the degradation of organic pollutants seems to be ascribable to the formation of ${ }^{\circ} \mathrm{OH}$ radicals released from the AuPd/CNTs catalytic system.

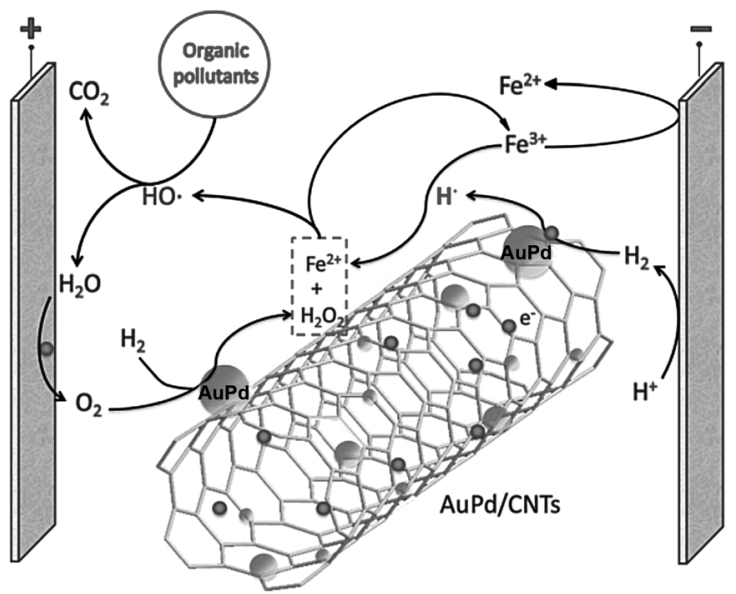

Scheme 1. Proposed mechanism in the AuPd/CNTs catalytic EF process.

Figure $6 \mathrm{~b}$ demonstrates the catalytic capacity of AuPd/CNTs for DMAC and phenol degradation. The degradation of phenol was also well fitted by pseudo-first-order kinetics. As a result, the removal of phenol was more effective $\left(k_{1}=0.026\right)$ than that of DMAC $\left(k_{1}=0.022\right)$, and phenol totally disappeared within $40 \mathrm{~min}$. However, the inset of Figure $6 \mathrm{~b}$ shows that at least $20 \%$ of the residual total organic carbon (TOC) remained after 60 min of phenol degradation and nearly $45 \%$ was left in DMAC degradation, which suggests incomplete mineralization of the organic pollutants. To understand the degradation pathway of organic pollutants based on the AuPd/CNTs catalytic EF process, HPLC was employed to separate the components of the treated bulk solution. Chemical standards corresponding to conceivable products, such as pyrocatechin and $p$-benzoquinone, were characterized prior to the analysis of intermediates. As shown in Figure $6 \mathrm{c}$, the peaks appearing at 5.6 and $4.8 \mathrm{~min}$ represent DMAC and its main intermediate acetamide, respectively. The peaks of acetamide increased rapidly from 10 to $20 \mathrm{~min}$ and decreased as the reaction proceeded from 20 to $40 \mathrm{~min}$. No high molecular weight substance was left at 50 min. Similarly, the main intermediates in phenol degradation are pyrocatechin and $p$-benzoquinone with corresponding peaks at 3.5 and $3.1 \mathrm{~min}$ (Figure $6 \mathrm{~d}$ ). The peak intensity of phenol declined quickly within $20 \mathrm{~min}$, and meanwhile the peaks of the two intermediates remained unchanged. Interestingly, the peaks of pyrocatechin and $p$-benzoquinone both decreased until $30 \mathrm{~min}$, which indicated that the accumulation and degradation rates of the intermediates were the same. In summary, it can be concluded from the above results that the components with high molecular weight are decomposed into 

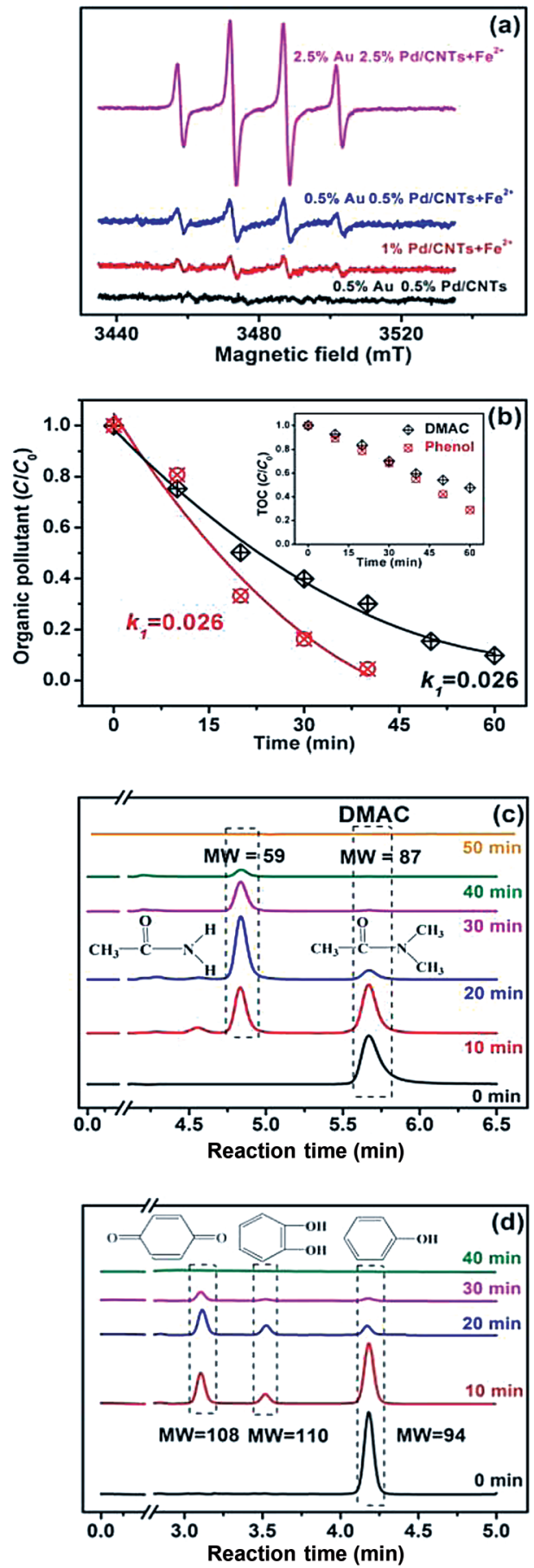

Figure 6. a) Production of ${ }^{\circ} \mathrm{OH}$ from different nanocatalysts measured by ESR. The samples for ESR measurement were obtained under reaction conditions: $1 \mathrm{~g} \mathrm{~L}^{-1}$ catalyst, initial $\mathrm{pH} 3,50 \mathrm{~mA} \mathrm{~cm}^{-2}$, and 30 min electrolysis. b) Changes of DMAC and phenol concentration during the catalytic EF process. $1 \mathrm{~g} \mathrm{~L}^{-1} 0.5 \% \mathrm{Au} 0.5 \% \mathrm{Pd} / \mathrm{CNT}$ catalysts, initial $\mathrm{pH} 3,50 \mathrm{mAcm}^{-2}$, and $100 \mathrm{mg} \mathrm{L}^{-1}$ initial DMAC and phenol. The inset shows the corresponding change of TOC. $C_{0}$ represents initial TOC; $C$ is the TOC with time. $c, d$ ) HPLC analysis of DMAC (c) and phenol (d) during the catalytic EF process as a function of time. Main intermediates were analyzed by addition of conceivable products as standard chemical reagents.

low molecular weight compounds through the AuPd/CNTs catalytic EF process. In addition, the residual TOC after 40 min of organic pollutant degradation can be attributed to the prod- ucts resulting from the further decomposition of intermediates, such as formic acid, acetic acid, and methanol. Fortunately, although these substances cannot be perfectly separated through HPLC, they are biodegradable.

\section{Conclusion}

In this work, AuPd/CNT heterogeneous nanocomposites used as three-dimensional electrodes during the EF process were successfully synthesized, which exhibited superior catalytic activity in the in situ production of $\mathrm{H}_{2} \mathrm{O}_{2}$ from $\mathrm{H}_{2}$ and $\mathrm{O}_{2}$, in situ regeneration of $\mathrm{Fe}^{2+}$, and excellent removal efficiency of organic pollutants. In sharp contrast with the performance of $\mathrm{Pd} /$ CNT nanocatalysts, appropriate loading of Au on AuPd/CNTs significantly elevated the catalytic activity under the same loading of noble metal. The main conclusions that can be drawn are given below.

A better pseudo-first-order rate constant for degradation of the probe organic pollutants was calculated $\left(0.050 \mathrm{~min}^{-1}, R^{2}=\right.$ 0.986 ) based on $0.5 \% \mathrm{Au} 0.5 \% \mathrm{Pd} / \mathrm{CNTs}$, compared with only $0.030 \mathrm{~min}^{-1}\left(R^{2}=0.995\right)$ for $1 \% \mathrm{Pd} / \mathrm{CNTs}$; the optimal in situ production of $\mathrm{H}_{2} \mathrm{O}_{2}$ from $0.5 \% \mathrm{Au} 0.5 \% \mathrm{Pd} / \mathrm{CNTs}$ was nearly $0.30 \mathrm{~mm}$ within $20 \mathrm{~min}$, but only $0.19 \mathrm{~mm}$ for $1 \% \mathrm{Pd} / \mathrm{CNTs}$; and the favorable in situ $\mathrm{Fe}^{2+}$ regeneration of $0.5 \% \mathrm{Au} 0.5 \% \mathrm{Pd} /$ CNTs implied the required initial $\mathrm{Fe}^{2+}$ dosage was only $0.05 \mathrm{~mm}$. The ideal catalytic efficiency peaked at initial $\mathrm{pH} 3$ and increased with increasing current density, whereas it decreased with increasing initial concentrations of DMAC and $\mathrm{Fe}^{2+}$. It was found that the introduction of $\mathrm{Au}$ on $\mathrm{AuPd} / \mathrm{CNT}$ nanocomposites enhanced the in situ synthesis of $\mathrm{H}_{2} \mathrm{O}_{2}$ and the catalytic efficiency of pollutant degradation. Au strengthens and stabilizes the nanostructure of AuPd nanocrystals and, theoretically, Au changes the structure of heterogeneous AuPd nanocrystals to give more exposure of atomic $\mathrm{H}$ chemisorbed on the active $\mathrm{Pd}(111)$ surface. The long durability of AuPd/CNTs over ten cycles in the catalytic EF process implied that AuPd/ CNTs had good catalytic stability and promise for engineering applications. A catalytic mechanism was proposed describing how AuPd/CNTs exhibited outstanding performance in the release of $\mathrm{OH}$ radicals during the catalytic EF process. Meanwhile, high molecular weight pollutants were decomposed into low molecular weight compounds through the AuPd/CNTs catalytic EF process.

\section{Experimental Section}

\section{Chemicals}

Dimethylacetamide (DMAC, $95 \mathrm{wt} \%)$ and phenol (99.5 wt \%), as the main probe organic contaminants, were purchased from Sinopharm Chemical Reagent Co., Ltd. (Shanghai, China). 5,5-Dimethyl1-pyrroline- $N$-oxide (DMPO) was provided by Aldrich. CNTs were obtained from Tsinghua University (Beijing, China). Palladium dichloride and chloroauric acid hydrate were supplied by Guoyao Group Chemical Reagent Co. Ltd., China. Ultrapure water was produced by a Millipore water purification system (Advantage A10, Millipore), with a resistivity of $\geq 18.2 \mathrm{M} \Omega \mathrm{cm}^{-1}$. Other chemical reagents were of at least analytical grade and used as received. 


\section{Catalyst synthesis}

The AuPd/CNT nanocomposites were synthesized by a one-step chemical solution deposition method. ${ }^{[28]}$ First, ultrapure water $(200 \mathrm{~mL})$ was placed in an Erlenmeyer flask at $80^{\circ} \mathrm{C}$ in a water bath with vigorous stirring at $800 \mathrm{rpm}$. Then, the prepared palladium dichloride solution, chloroauric acid hydrate solution (the weights of $\mathrm{Pd}$ and $\mathrm{Au}$ were varied proportionally), and activated CNTs were added rapidly to the flask. The mixture was held in the vessel for $6 \mathrm{~h}$ at $80^{\circ} \mathrm{C}$ followed by $30 \mathrm{~min}$ of ultrasonic treatment. The resulting homogeneous, dark black suspension was further treated by dropwise addition of sodium borohydride $(10 \mathrm{~mL}, 1 \mathrm{M})$. Finally, the mixture was held for $3 \mathrm{~h}$ at $80^{\circ} \mathrm{C}$, then the sediments removed by filtration. The precipitates were washed by ultrapure water and dried at room temperature. The integrated AuPd/CNTs with specific AuPd loading were thus obtained.

\section{Catalytic activity tests}

The electrolytic trial was conducted in a conventional undivided cylindrical cell of $150 \mathrm{~mL}$ capacity at $(25 \pm 1)^{\circ} \mathrm{C}$. A dimensionally stable anode (DSA) and a stainless steel cathode $(2.5 \times 5.0 \mathrm{~cm})$ were used with a spacing of $3 \mathrm{~cm}$. The probe solution was stirred with a Teflon-coated magnetic bar at 400 rpm to ensure homogenization and transport of reactants and catalysts towards/from the electrodes. A constant electric current from 10 to $1000 \mathrm{~mA}$ was applied with a cell potential from 3 to $8 \mathrm{~V}$. All the electrodes had been previously polarized in $0.1 \mathrm{M} \mathrm{Na}_{2} \mathrm{SO}_{4}$ at $200 \mathrm{~mA}$ within $30 \mathrm{~min}$ to remove impurities. For each test, the probe solution $(100 \mathrm{~mL})$ was transferred into the electrolytic cell, and then $\mathrm{Na}_{2} \mathrm{SO}_{4}$ powder $(2.13 \mathrm{~g})$ and AuPd/CNTs (0.1) were dropped simultaneously into the vessel. The solution was constantly stirred at $400 \mathrm{rpm}$ after ultrasonic treatment for $10 \mathrm{~min}$. Subsequently, $1 \mathrm{M} \mathrm{H}_{2} \mathrm{SO}_{4}$ was injected to adjust the initial $\mathrm{pH}$ to 3 . Samples of about $1 \mathrm{~mL}$ were collected periodically at intervals and filtered by filter paper $(0.45 \mu \mathrm{m})$ for chemical analysis. All experiments were carried out in duplicate. The performance of the EF process using the AuPd/CNTs was further evaluated by degrading DMAC $\left(20,100,250\right.$, and $\left.500 \mathrm{mg} \mathrm{L}^{-1}\right)$ under various conditions: different current densities $(12.5,25,50$, and $100 \mathrm{mAm}^{-2}$ ), loading of Au on AuPd/CNTs $(0,0.25,0.5,0.75$, and $1.0 \mathrm{wt} \% \mathrm{Au})$, initial $\mathrm{pH}(2,3,4,5,6$, and 7$)$, and ferrous dosages $(0,0.05,2.5,5$, and $10 \mathrm{~mm})$. The efficiency of AuPd/CNTs after repeated use was finally tested by degradation of DMAC and phenol independently for ten cycles under optimized conditions. The tested AuPd/CNTs were recycled by filtration and washing with ultrapure water.

\section{Analytical methods}

Powder X-ray diffraction (XRD) of the AuPd/CNTs was recorded on a D8 Advance (Bruker) X-ray diffractometer with $\mathrm{Cu}_{k \alpha}$ radiation $(\lambda=$ $1.54059 \AA)$. The step size and scan rate were set at $0.05^{\circ}$ and $0.025^{\circ} \mathrm{s}^{-1}$, respectively. $\mathrm{N}_{2}$ adsorption-desorption was conducted at $77 \mathrm{~K}$ using a Brunauer-Emmett-Teller (BET) surface area apparatus (Micromeritics ASAP2020). Scanning electron microscopy (SEM) was performed on an FEI Sirion 200 scanning electron microscope. Transmission electron microscopy coupled with energy-dispersive $\mathrm{X}$-ray spectrometry (TEM/EDX) and high-resolution transmission electron microscopy (HRTEM) images were obtained with a TEM $\mathrm{H}-800$ instrument (Hitachi, Japan) at an accelerating voltage of $200 \mathrm{kV}$. The X-ray photoelectron spectroscopy (XPS) data were taken on an AXIS-Ultra instrument (Kratos Analytical, UK) using monochromatic $\mathrm{Al}_{\mathrm{k} \alpha}$ radiation $(225 \mathrm{~W}, 15 \mathrm{~mA}, 15 \mathrm{kV})$ and lowenergy electron flooding for charge compensation. Cyclic voltam- metry of CNTs, Pd/CNTs, and AuPd/CNTs was performed at a scan rate of $50 \mathrm{mV} \mathrm{s}^{-1}$ between 1.2 and $-0.2 \mathrm{~V}$ in $\mathrm{H}_{2}$ - and $\mathrm{O}_{2}$-saturated acidic solution by using a $\mathrm{CHI} 830$ electrochemical analyzer $(\mathrm{CHI}$, Inc., USA). DMAC, phenol, and their degradation products were analyzed by reversed-phase high-performance liquid chromatography (HPLC) with a Hitachi HPLC apparatus (diode-array detector L-2450, column oven L-2300, and pump L-2130). The mobile phase for DMAC was a mixture of methanol and water $(30: 70, v / v)$. The flow rate was $0.6 \mathrm{~mL} \mathrm{~min}^{-1}$ and the detection wavelength was set at $220 \mathrm{~nm}$. As for phenol, the mobile phase consisted of acetonitrile and water $(50: 50, \mathrm{v} / \mathrm{v})$ at $1 \mathrm{~mL} \mathrm{~min}{ }^{-1}$. The detection wavelength was $210 \mathrm{~nm}$. The 1,10-o-phenanthroline colorimetric method was employed to determine ferrous ion content at $510 \mathrm{~nm}$. The concentration of total organic carbon (TOC) was measured using a multi N/C 3000 TOC analyzer (Analytik Jena AG, Germany). Electron spin resonance (ESR) spectra were utilized to indirectly determine the concentration of generated ${ }^{\circ} \mathrm{OH}$ using DMPO as the scavenger. The operating parameters of the electron paramagnetic resonance spectrometer (ESP 300E, Bruker) were: center field, $3480.00 \times \mathrm{G}$; microwave frequency, $9.79 \mathrm{GHz}$; power, $5.05 \mathrm{~mW} .^{[29,30]}$

\section{Acknowledgements}

This work was supported financially by the Major Program of the National Natural Science Foundation of China (No. 51290282), National Basic Research Program of China (No. 2011CB935704, No. 2013CB934004), and National Natural Science Foundation of China (No. 21235004).

Keywords: electro-Fenton process - gold - nanotubes palladium $\cdot$ supported catalysts

[1] a) J. Wei, Y. Song, X. Tu, L. Zhao, E. Zhi, Chem. Eng. J. 2013, 218, 319 326; b) M. M. Ghoneim, H. S. El-Desoky, N. M. Zidan, Desalination 2011 274, $22-30$; c) W. P. Ting, M. C. Lu, Y. H. Huang, J. Hazard. Mater. 2009, 161, 1484- 1490.

[2] a) M. Y. A. Mollah, R. Schennach, J. R. Parga, D. L. Cocke, J. Hazard. Mater. 2001, 84, 29-41; b) J. R. Parga, D. L. Cocke, V. Valverde, J. A. G. Gomes, M. Kesmez, H. Moreno, M. Weir, D. Mencer, Chem. Eng. Technol. 2005 28,605-612; c) M. Ma, R. Liu, H. Liu, J. Qu, W. Jefferson, Sep. Purif. Tech nol. 2012, 86, 19-25; d) X. Zhao, H. Liu, A. Li, Y. Shen, J. Qu, Electrochim. Acta 2012, 62, 181-184; e) C. Zhang, J. Wang, H. Zhou, D. Fu, Z. Gu, Chem. Eng. J. 2010, 161, $93-98$.

[3] P. V. Nidheesh, R. Gandhimathi, Desalination 2012, 299, 1-15.

[4] E. Brillas, I. Sirés, M. A. Oturan, Chem. Rev. 2009, 109, 6570-6631.

[5] a) M. Luo, S. Yuan, M. Tong, P. Liao, W. Xie, X. Xu, Water Res. 2014, 48 190-199; b) S. Yuan, M. Chen, X. Mao, A. N. Alshawabkeh, Water Res. 2013, 47, 269-278; c) P. Liao, S. Yuan, M. Chen, M. Tong, W. Xie, P. Zhang, Environ. Sci. Technol. 2013, 47, 7918-7926; d) S. Yuan, Y. Fan, Y. Zhang, M. Tong, P. Liao, Environ. Sci. Technol. 2011, 45, 8514-8520.

[6] S. Yuan, X. Mao, A. N. Alshawabkeh, Environ. Sci. Technol. 2012, 46, $3398-3405$.

[7] C. Xu, Y. Zhang, L. Wang, L. Xu, X. Bian, H. Ma, Y. Ding, Chemistry of Materials 2009, 21, 3110-3116.

[8] D. Ferrer, A. Torres-Castro, X. Gao, S. Sepúlveda-Guzmán, U. OrtizMéndez, M. José-Yacamán, Nano Lett. 2007, 7, 1701-1705.

[9] Y. Xiang, X. Wu, D. Liu, X. Jiang, W. Chu, Z. Li, Y. Ma, W. Zhou, S. Xie, Nano Lett. 2006, 6, 2290-2294.

[10] J. Yang, H. I. Elim, Q. Zhang, J. Y. Lee, W. Ji, J. Am. Chem. Soc. 2006, 128, $11921-11926$.

[11] A. Staykov, T. Kamachi, T. Ishihara, K. Yoshizawa, J. Phys. Chem. C 2008, $112,19501-19505$.

[12] Y.-F. Han, Z. Zhong, K. Ramesh, F. Chen, L. Chen, T. White, Q. Tay, S. N. Yaakub, Z. Wang, J. Phys. Chem. C 2007, 111, 8410-8413. 
[13] a) J. Xiao, L. Wan, X. Wang, Q. Kuang, S. Dong, F. Xiao, S. Wang, J. Mater Chem. A 2014, 2, 3794-3800; b) J. Xu, D. Aili, Q. Li, C. Pan, E. Christensen, J. O. Jensen, W. Zhang, G. Liu, X. Wang, N. J. Bjerrum, J. Mater. Chem. A 2013, 1, 9737-9745; c) F. J. Pérez-Alonso, M. A. Salam, T. Herranz, J. L. Gómez de La Fuente, S. A. Al-Thabaiti, S. N. Basahel, M. A. Peña, J. L. G. Fierro, S. Rojas, J. Power Sources 2013, 240, 494-502.

[14] D. Eder, Chem. Rev. 2010, 110, 1348-1385.

[15] W. Chen, X. Pan, X. Bao, J. Am. Chem. Soc. 2007, 129, 7421-7426.

[16] D. H. Youn, S. Han, J. Y. Kim, J. Y. Kim, H. Park, S. H. Choi, J. S. Lee, ACS Nano 2014, 8, 5164-5173.

[17] Y. Zhang, N. Zhang, Z.-R. Tang, Y.-J. Xu, J. Phys. Chem. C 2014, 118 5299-5308.

[18] A. Cybula, J. B. Priebe, M.-M. Pohl, J. W. Sobczak, M. Schneider, A. Zielińska-Jurek, A. Brückner, A. Zaleska, Appl. Catal. B 2014, 152-153, 202 211.

[19] G. Zhao, S. Shen, M. Li, M. Wu, T. Cao, D. Li, Chemosphere 2008, 73, $1407-1413$

[20] H. C. Ham, G. S. Hwang, J. Han, S. W. Nam, T. H. Lim, J. Phys. Chem. C 2009, 113, 12943-12945.

[21] Y. Fu, Z. D. Wei, S. G. Chen, L. Li, Y. C. Feng, Y. Q. Wang, X. L. Ma, M. J. Liao, P. K. Shen, S. P. Jiang, J. Power Sources 2009, 189, 982-987.
[22] J. S. Jirkovský, I. Panas, E. Ahlberg, M. Halasa, S. Romani, D. J. Schiffrin, J. Am. Chem. Soc. 2011, 133, 19432-19441.

[23] W.-P. Ting, M.-C. Lu, Y.-H. Huang, J. Hazard. Mater. 2008, 156, 421-427.

[24] a) Z. Qiang, J.-H. Chang, C.-P. Huang, Water Res. 2003, 37, 1308-1319; b) Z. Qiang, J.-H. Chang, C.-P. Huang, Water Res. 2002, 36, 85-94.

[25] J. H. Ramirez, F. M. Duarte, F. G. Martins, C. A. Costa, L. M. Madeira, Chem. Eng. J. 2009, 148, 394-404.

[26] a) W. Liu, Z. Ai, L. Zhang, J. Hazard. Mater. 2012, 243, 257-264; b) F. Zhao, L. Liu, F. Yang, N. Ren, Chem. Eng. J. 2013, 230, 491-498.

[27] A. Babuponnusami, K. Muthukumar, Chem. Eng. J. 2012, 183, 1-9.

[28] T. Balcha, J. R. Strobl, C. Fowler, P. Dash, R. W. J. Scott, ACS Catal. 2011, $1,425-436$

[29] S. Horikoshi, H. Hidaka, N. Serpone, Chem. Phys. Lett. 2003, 376, $475-$ 480.

[30] F. Chen, X. Zhao, H. Liu, J. Qu, Appl. Catal. B 2014, 158, 85-90.

Received: December 30, 2014

Published online on April 1, 2015 